\title{
Saúde coletiva, território e conflitos ambientais: bases para um enfoque socioambiental crítico
}

\author{
Collective health, territorial and environmental conflicts: \\ bases for a critical socio-environmental approach
}

Marcelo Firpo de Souza Porto ${ }^{1}$

Diogo Ferreira da Rocha ${ }^{1}$

Renan Finamore ${ }^{1}$

${ }^{1}$ Centro de Estudos da Saúde do Trabalhador e Ecologia Humana, Escola Nacional de Saúde Pública Sérgio Arouca, Fundação Oswaldo Cruz. R. Leopoldo Bulhões 1480, Manguinhos. 21.041-210 Rio de Janeiro RJ Brasil.marcelo.firpo@ ensp.fiocruz.br

\begin{abstract}
The phenomenon of globalization and the increase in neo-extractivism in the global periphery intensify the search for new territories and natural resources for the economy, resulting in significant impacts on ecosystems and on the lives of vulnerable populations. It is considered that the environmental crisis imposes new challenges and requires an updating of the theoretical and methodological foundations of collective health and the social determinants of health. The scope of this paper is to present theoretical contributions to the construction of a critical socio-environmental approach from a review of the literature structured around previous work on the mapping of environmental conflicts, and conducting empirical studies in conflicting areas. The contributions of sociology, political ecology, postcolonial studies and geography is summarized for the discussion of the socio-environmental determinants of health, as well as experiences that integrate emancipatory knowledge, political subjects, resistances and alternatives for society.

Key words Conflicts, Environmental justice, Social determinants of health, Territoriality, Knowledge production
\end{abstract}

Resumo O fenômeno da globalização e o crescimento do neoextrativismo na periferia global intensificam a demanda por novos territórios $e$ recursos naturais à economia, resultando em significativos impactos sobre os ecossistemas e a vida das populações vulnerabilizadas. Consideramos que a crise socioambiental impõe novos desafios e exige uma reatualização das bases teórico-metodológicas da saúde coletiva e dos determinantes sociais da saúde. O objetivo deste artigo é apresentar aportes teóricos para a construção de um enfoque socioambiental crítico a partir de uma revisão bibliográfica orientada por experiências anteriores de mapeamento de conflitos ambientais e pela realização de estudos empíricos em áreas conflituosas. Apresentamos contribuições de disciplinas como a sociologia, a ecologia política, os estudos pós-coloniais e a geografia, para a discussão da determinação socioambiental da saúde, bem como experiências de construção de conhecimentos emancipatórios que integram sujeitos politicos, resistências e alternativas para a sociedade.

Palavras-chave Conflitos, Justiça ambiental, Determinação social da saúde, Territorialidade, Produção de conhecimento 


\section{Introdução: a Saúde Coletiva em tempos de crise socioambiental}

A Saúde Pública é historicamente marcada pela disputa por hegemonia entre, de um lado, teorias de base estruturalista, com ênfase nas relações sociais e ecológicas; de outro, as que enfatizam dimensões biológicas e individuais, ao analisar tendências relativas à distribuição de riscos, doenças, incapacidades e mortes nas populações. As estratégias de planejamento e políticas públicas no campo oscilam, ora enfatizando a saúde como resultado de políticas sociais numa sociedade em transformação, ora como restrita à eficiência de tecnologias e serviços de saúde ou medidas pontuais de prevenção e promoção. $\mathrm{O}$ avanço de áreas como a microbiologia, imunologia e farmacologia, com a criação de tecnologias, vacinas e medicamentos, contribuiu para um clima otimista em relação às potencialidades da biomedicina que deu origem ao modo hegemônico de se pensar a saúde públicaa ${ }^{1,2}$. Outro importante elemento foi o fortalecimento da epidemiologia, que incorporou os avanços dos métodos estatísticos de coleta e análise de dados nos estudos a respeito da distribuição das doenças e das epidemias, bem como a análise de causas e efeitos a partir das possíveis associações entre atributos individuais ou coletivos, formas de exposição e desfechos.

A perspectiva biomédica e epidemiológica produziu uma racionalidade para as intervenções da sociedade e do Estado nos moldes de uma ciência normal ${ }^{3}$, restringindo a dimensão social na determinação do processo saúde-doença "ao plano instrumental dos atributos" ${ }^{\prime}$, com a sociedade sendo entendida como um agregado de indivíduos com características quantificáveis. Tal racionalidade não prioriza nem articula melhorias das condições de vida e trabalho com as estruturas sociais da sociedade ou laços de solidariedade.

Nos anos 1970 emerge, na interface entre o campo da saúde pública e as lutas sociais, a chamada medicina social latino-americana (MSLA). Influenciada pelo estruturalismo materialista, ela avança na crítica ao paradigma biomédico hegemônico e seus limites frente às contradições existentes nas sociedades latino-americanas da época, que viviam em sua maioria sob regimes autoritários, que simultaneamente geravam crescimento econômico e aprofundavam as desigualdades sociais e de saúde. A perspectiva da MSLA recusava a delimitação das populações a partir de dados de base individual, optando por uma visão crítica na qual a população é definida como uma totalidade determinada pelo contexto social. Para tanto, toma como principais categorias de análise a reprodução social, classe social, ideologia, produção econômica, cultura, etnia e gênero. Estas categorias orientavam as análises dos aspectos individuais existentes na população, tais como sexo, idade, nível educacional, renda ou raça ${ }^{5}$.

Nas décadas seguintes, a América Latina, em particular o Brasil, irá vivenciar múltiplas e complexas influências que explicam o surgimento da Saúde Coletiva no país, suas contradições e desafios atuais. A luta pela redemocratização caminhou pari passu com o movimento sanitarista, a criação da Abrasco e do SUS, com inúmeros avanços em termos acadêmicos e institucionais. Contudo, na Nova República e principalmente nos governos Collor e FHC, a institucionalidade conquistada se confronta com forças políticas conservadoras e a ideologia neoliberal em tempos de descrédito do materialismo histórico ortodoxo pós-muro de Berlim. Paradoxalmente, isso não destrói os pilares do campo e do recém-criado SUS, mas fortalece, por vezes veladamente, resistências e críticas ao modelo da MSLA ${ }^{6}$. As tensões entre os polos estrutural crítico e biomédico tendem a se diluir por uma convivência acrítica, com perda da vitalidade das inovações que emergiram a partir dos anos 1980, como a luta antimanicomial, a relação com movimentos sociais para o controle social do SUS, a relação com o movimento sindical na criação da saúde dos trabalhadores, a produção teórica da epidemiologia social crítica, a renovação das áreas de vigilância e a proposição de uma vigilância da saúde que nunca se concretizou. A crescente especialização do campo, sua legitimação acadêmica na CAPES, discussões específicas como financiamento e mecanismos de gestão do SUS, estes e outros temas formaram uma agenda que pouco contribuiu para revitalizar os referenciais críticos e práticas criativas que fundaram a Saúde Coletiva.

Nas últimas três décadas, também houve o reconhecimento da crise socioambiental e dos riscos ecológicos globais, gerando noções como desenvolvimento sustentável e acordos internacionais que pautam agendas políticas, movimentos sociais, políticas públicas e a própria saúde coletiva. Além do ambientalismo, ressurgem ou emergem movimentos sociais que trazem novas bandeiras e sujeitos políticos à luta social: o enfrentamento de questões de gênero e sexualidade, étnicas, contra o racismo e o machismo, pela reforma agrária, direito à cidade, dentre outros.

Os anos 1990 também foram marcados por propostas de redução da intervenção estatal na economia e o crescente abandono de medidas de 
substituição de exportações e industrialização. Revigora-se o papel subordinado da América Latina no fornecimento de commodities agrícolas e minerais que alimentam políticas tecnológicas, industriais e de concentração de renda em benefício das elites mundiais e dos países do Norte. Gudynas ${ }^{7}$ denomina de neoextrativismo tal modelo, o qual baseia-se em cadeias produtivas pouco diversificadas que se apropriam dos recursos naturais, industrializam e mercantilizam a natureza. Nesse contexto, a agenda ambiental pós Rio 92 é fortemente restringida pelo modelo centrado em atividades econômicas como o agronegócio, a mineração e indústrias de beneficiamento, a produção de energia, infraestruturas de transporte e irrigação, áreas preservadas para o ecoturismo ou mecanismos como o mercado de carbono. A isso devemos adicionar problemas como a moradia insalubre e a falta de saneamento básico, os acidentes de trânsito, a poluição urbana e de corpos hídricos, além da violência e segurança pública, formando uma complexa agenda socioambiental para o país que interage fortemente com a saúde coletiva.

Nesse contexto, o Estado assume um papel contraditório: de um lado implementa políticas públicas voltadas aos direitos fundamentais através de limitadas políticas redistributivas, sociais e do SUS, em especial com a ascendência do PT. Diversos outros países da América Latina com governos mais progressistas nos últimos anos se legitimam por meio de políticas sociais e redistributivas que melhoram indicadores como o IDH. Isso é fortemente influenciado pelo superávit fiscal obtido em função da estabilidade dos preços das commodities nos últimos anos, o chamado efeito China ${ }^{8}$, embora as políticas de austeridade na Europa pós-crise de 2008 e a tendência à diminuição do ritmo de crescimento na China fragilizem essa estratégia.

O outro lado da moeda é o papel do mesmo Estado nas políticas econômicas, tecnológicas e educacionais que sustentam o modelo hegemônico, aliando-se a grupos sociais conservadores e corporações transnacionais, o que resulta em flexibilização dos marcos jurídicos conquistados para a proteção do trabalhador, do meio ambiente e a garantia dos direitos fundamentais, em especial de indígenas, quilombolas e camponeses. $\mathrm{O}$ resultado é a intensificação dos conflitos territoriais pela inserção capitalista destrutiva e concentradora nos diversos espaços da vida social, sejam campos e florestas ou nas cidades subordinadas às cadeias produtivas ou aos megaeventos globais. Conflitos territoriais e ambientais, proces- sos de vulnerabilização, movimentos por Justiça Ambiental (JA) e o próprio sentido de desenvolvimento passam a impulsionar a agenda política e científica em diferentes campos, inclusive o da saúde. Não é casual, portanto, que a temática saúde e ambiente tensione as bases da Saúde Coletiva contemporânea e aponte novas questões para repensar seus fundamentos teóricos e práticas em tempos de crise e transformação.

\section{Bases para a construção de um enfoque socioambiental crítico e transformador}

Diante do exposto consideramos necessário repensar as bases e alternativas políticas, teóricas e práticas da Saúde Coletiva a partir das contribuições provenientes do debate socioambiental, e buscamos sistematizar alguns elementos para a construção de um enfoque socioambiental crítico e transformador. Um ponto de partida é o debate sobre a determinação social da saúde e as questões ainda abertas que levaram a formulação da MSLA, assim como os limites e a ineficácia do modelo hegemônico biologizante e individual. Álvarez Castaño ${ }^{9}$ organiza em três grupos as perspectivas teóricas que analisam os determinantes das inequidades sociais em saúde, isto é, as diferenças no estado de saúde das pessoas que são evitáveis e injustas: (i) o psicossocial considera que, em sociedades desiguais, a percepção das discriminações vividas por certos grupos sociais e as redes de apoio social desempenham um importante papel sobre a saúde; (ii) o de base materialista-estruturalista, focado na produção de desigualdades pelas sociedades capitalistas, materializadas em condições de vida e trabalho precárias, maior exposição aos riscos ambientais e menor adesão a medidas preventivas ou acesso aos serviços de saúde; (iii) o ecossocial, que integra elementos anteriores desde uma visão sistêmica, para construir uma plataforma teórica multinível a partir dos níveis de organização social e biológica, que condicionam a situação de saúde individual e populacional. Importantes contribuições de autores da América Latina ${ }^{10,11} \mathrm{e}$ norteamericanos ${ }^{12,13}$ ilustram esta perspectiva.

Diante desse quadro, uma lacuna importante para a compreensão sobre a determinação social da saúde é o fosso existente entre o plano macroestrutural e coletivo, e as condições e potencialidades dos sujeitos em planos mais pessoais e comunitários vinculados ao cotidiano e ao lugar. Um esforço importante tem sido a aproximação com o estruturalismo-construtivista, o que fornece elementos para compreendermos as 
diferentes possibilidades de interação entre os diversos sujeitos que participam na produção de conhecimentos e práticas. Por exemplo, Buzzelli ${ }^{14}$ utiliza o conceito de "espaço social" de Pierre Bourdieu como uma forma de reafirmar a multidimensionalidade da estrutura social na análise dos problemas de saúde. Rompe, simultaneamente, com a tendência de muitas teorias de base marxista em "reduzir o campo social unicamente ao campo econômico", e com o objetivismo "que leva a ignorar as lutas simbólicas desenvolvidas nos diferentes campos"15. Além disso, o conceito bourdieuniano de habitus permite construir uma ponte epistemológica entre a estrutura social e a agência, recuperando a noção dos sujeitos como produtos de trajetórias individuais inseridas na História, mas não por ela exclusivamente determinada. O habitus reflete as disposições adquiridas mediante a interação social e, ao mesmo tempo, é o classificador e organizador desta interação, sendo condicionante e condicionador das nossas ações ${ }^{16}$. Tal perspectiva nos permite considerar a inovação sem ignoramos os constrangimentos sociais à ação de cada indivíduo, ampliando a compreensão de autonomia e práticas emancipatórias em sintonia com as propostas pedagógicas de Paulo Freire.

Contudo, a ampliação do escopo da determinação social da saúde será incompleto se não superarmos uma visão estrita da dimensão ecológica que desconsidera as relações sociais. Para isso são fundamentais enfoques que integrem questões de saúde e ambiente aos direitos humanos, territoriais e sociais. A emergência desse debate está intimamente relacionada ao reconhecimento do atual contexto como marcado pelo rápido desenvolvimento econômico e tecnológico voltado para a apropriação intensiva dos recursos naturais, econômicos e sociais ${ }^{17}$. Ao mesmo tempo, a produção moderna intensifica sua dependência dos sistemas e tecnologias perigosos, com riscos para a saúde dos trabalhadores e das populações no entorno.

A expansão irresponsável de fronteiras em territórios outrora ocupados por indígenas, quilombolas e camponeses, dentre outros, leva à desestruturação das relações sociais, organizações comunais e modos de vida tradicionais dessas populações. Estes são muitas vezes constituídos historicamente à margem das garantias jurídicas ou da economia formal, a partir de relações sociais com base na confiança mútua, no compadrio ou no estabelecimento de costumes e restrições a respeito de áreas de uso comum, sendo os conhecimentos sobre os ecossistemas transmiti- dos às novas gerações a partir de mecanismos de reprodução cultural e na experiência do trabalho. Essas economias locais são violentamente desorganizadas, inclusive com assassinatos, para que esses territórios se integrem à economia capitalista globalizada, que desterritorializa as relações socioeconômicas locais e as reterritorializa a partir de novos códigos e signos. Dinâmicas territoriais homogeneizadoras formam um território -mundo ${ }^{18}$ que impõe, sob uma lógica mercantil, novos tempos e racionalidades que desconsideram as especificidades do território, incluindo seus ecossistemas, povos, cosmovisões e cultura.

Todos esses processos interagem de forma complexa e produzem injustiças ambientais, entendidas aqui como os mecanismos pelo quais sociedades desiguais destinam a maior carga dos danos ambientais do desenvolvimento às populações marginalizadas e vulnerabilizadas ${ }^{19}$. Os aportes teóricos da Ecologia Política ${ }^{20,21}$, um campo interdisciplinar que incorpora contribuições da economia política, das ciências sociais e da ecologia, ajudam a compreender tais processos ao analisar as relações de poder que beneficiam importantes grupos econômicos e políticos globais, que se sustentam a partir de recursos não -locais, intensificando o metabolismo social, excluindo populações locais e estabelecendo novas periferias entre e dentro dos países.

Tal discussão permite pensar a complexidade e conceitos como vulnerabilidade numa perspectiva crítica e emancipatória. Mais que atributos que definem pessoas e grupos mais ameaçados ou predispostos a problemas de saúde, em função de sua incapacidade de se defenderem, é importante analisar e intervir nos processos que vulnerabilizam os sujeitos ${ }^{22,23}$. Isto significa superar a tendência a considerar tais populações como passivas e abstratas para situá-las como sujeitos políticos e históricos, culturalmente situados, detentores de direitos. Amplia-se, assim, a concepção de saúde, sua determinação e práxis, já que, na maioria dos casos, envolve disputa por poder político, inserção em processos decisórios, definição de políticas públicas e novas epistemes.

A noção de conflito ambiental é estratégica por permitir a análise das disputas entre grupos sociais por objetivos e interesses conflitantes no uso do território e dos recursos naturais existentes, incluindo, além dos agentes econômicos e populações, as instituições estatais. Enquanto inúmeras injustiças ambientais permanecem invisibilizadas pela força aniquiladora do poder político e econômico, somada às dificuldades de mobilização das comunidades e populações afe- 
tadas, os conflitos surgem justamente pela emergência de formas organizadas de resistência e afirmação de outros projetos de desenvolvimento e sociedade. Portanto, os conflitos são mediados por outras variáveis além do poder político, como renda e capital simbólico, e são atravessados por valores muitas vezes inegociáveis e incomensuráveis, incluindo a cultura e dimensões do viver e morrer que ampliam a noção de saúde enquanto componente das políticas da vida ${ }^{24}$.

Conflitos ambientais, por vezes, também são territoriais, o que reforça o diálogo com a geografia política e da saúde já iniciados com os estudos sobre a espacialização das tendências epidemiológicas ou das estratégias territorializadas de organização do SUS. Para além das fronteiras do Estado-Nação e níveis federativos, a noção de territorialidade ganha importância por estar ligada ao modo como as pessoas utilizam a terra, se organizam no espaço e dão significado ao lugar. Haesbaert (apud Monken et al. ${ }^{25}$ ) vai além e admite a coexistência de vários tipos de território dependendo dos fundamentos ligados ao controle e/ou apropriação do espaço, sejam eles políticos, econômicos e culturais, cada qual com uma dinâmica própria. Dessa forma, um mesmo espaço pode conter diversas territorialidades que podem envolver territórios temporários, permanentes, intermitentes, estáveis, instáveis, contínuos, descontínuos, com expressão em diferentes escalas. Por isso, intenção, apropriação, poder, delimitação e identidade são alguns elementos chaves para compreendermos o território e suas relações com a saúde ${ }^{25}$.

Numa outra frente, os estudos pós-coloniais que se consubstanciam nos anos 2000 no denominado grupo Modernidade/Colonialidade representam uma novidade teórica que pode iluminar alguns debates teóricos da Saúde Coletiva. Sua origem provém de autores asiáticos e africanos no campo da cultura e literatura, como o palestino Edward Said, o indiano Homi Bhabha e o afro-francês Frantz Fanon. Na América Latina autores proeminentes são Aníbal Quijano, Walter Mignolo, Nelson Maldonado-Torres, Edgardo Lander, Arturo Escobar e Enrique Dussel. Especificamente na língua portuguesa destacamse os trabalhos de Boaventura de Sousa Santos e as discussões realizadas por Carlos Walter PortoGonçalves ${ }^{26-28}$.

Para essa escola "o fim do colonialismo político, enquanto forma de dominação que envolve a negação da independência política de povos e/ou nações subjugados, não significou o fim das relações sociais extremadamente desiguais que ele tinha gerado"29. Ou seja, o colonialismo mantém-se sob a forma da "colonialidade" e é constitutivo do padrão mundial do poder capitalista contemporâneo, e que se articula às noções de raça e racismo ${ }^{27}$. A renovação do pensamento emancipador supõe reconhecer e superar as lógicas da colonialidade do poder, ser e saber, e também resgatar e valorizar outras experiências políticas, vivências culturais, alternativas econômicas e de produção de conhecimentos ${ }^{28}$. $\mathrm{E}$ isso se realiza através de uma profunda interação com a gramática dos movimentos e lutas sociais dos povos subalternizados em seus contextos culturais e territoriais, como estratégia de superação da característica abissal do pensamento ocidental moderno, que relega o conhecimento nativo dos territórios colonizados à invisibilidade e ignorância. Tal gramática revela que o mundo é constituído por muitos mundos visíveis ou ocultos, e que a modernidade foi antes uma transmodernidade, negada e discriminada pelos interesses e tradições imperiais e coloniais da cultura eurocêntrica. Nesse contexto surgem propostas como as desobediências epistêmicas, sociologias das ausências e das emergências, diálogos e ecologia dos saberes ${ }^{30,31}$, as quais podem iluminar a saúde coletiva ao reconhecerem no saber das comunidades em conflito um “outro" possível e necessário ao conhecimento emancipador.

\section{Da teoria à ação: alternativas para a produção de conhecimentos emancipatórios}

As alternativas para a produção de conhecimentos a partir dos referenciais apresentados gravitam em torno do que denominamos epistemologia política ${ }^{23}$. Ela reconhece que problemas de saúde e sua determinação socioambiental são complexos e multidimensionais, pois envolvem simultaneamente questões sociopolíticas, econômicas, culturais e biológicas, dentre outras, o que implica aceitar uma pluralidade de perspectivas teóricas e metodológicas legítimas.

A noção de uma epistemologia política vai além do pensamento sistêmico formulado a partir de níveis abstratos de organização da vida social, comunitária ou individual, ou ainda de fluxos materiais e energéticos em suas conexões com o mundo biológico e ecossistêmico. Ela tem sentido na medida em que há um envolvimento de corpo e alma entre os distintos sujeitos cognoscentes, reconhecendo a condição humana em que todos podemos ser aprendizes em busca de autonomia e liberdade. O desafio é romper com 
separações, dicotomias e hierarquias discriminatórias que bloqueiam interações, diálogos e intencionalidades para uma ação conjunta. Problemas de saúde e ambiente abarcam uma contínua busca de compreensão e ressignificação das necessidades e possibilidades de transformação social em contextos de conflitos socioambientais, seja pelo enfrentamento das ameaças à vida e à saúde, seja pela reafirmação das alternativas de sua promoção. Nessa perspectiva, a superioridade do saber científico é questionada como forma de dominação quando não reconhece outras visões de mundo e experiências, o que bloqueia outros futuros possíveis.

O tema da tradução surge, então, em outros termos. Por exemplo, na perspectiva pós-colonial trata-se, como afirma Santos ${ }^{31}$, de um trabalho simultaneamente intelectual e político, emocional ou subjetivamente engajado no sentido do inconformismo e vontade de superação perante a incompletude ou deficiência de um dado conhecimento ou prática. Tradutores são sujeitos individuais e coletivos para a transdisciplinaridade e transculturalidade, pois estabelecem pontes não só entre paradigmas científicos, mas entre culturas, valores e linguagens na busca de compreensão e ressignificação dos problemas diante de insatisfações e necessidades de mudanças. Eles circulam por e dominam, em algum grau, diferentes paradigmas e linguagens, sendo casos exemplares educadores ambientais ou agentes comunitários de saúde que dominam saberes locais; investigadores engajados que dialogam com comunidades e movimentos sociais, na busca de compromissos e convergências construídos por meio de práticas ativistas e métodos de pesquisa-ação; ou ainda casos de fusão dos dois grupos anteriores, de cientistas provenientes de classes sociais, grupos raciais ou étnicos que elegem como objetos de pesquisa questões provenientes de suas comunidades de origem.

Diversas alternativas para a produção de conhecimentos vêm sendo desenvolvidas por comunidades atingidas e organizações de justiça ambiental, em conjunto com cientistas e profissionais solidários às suas reivindicações. Um primeiro passo consiste em avançar nas concepções que desconsideram a multidimensionalidade dos problemas e não se sensibilizam frente ao sofrimento, clamores e saberes das populações atingidas. A visão pouco dialógica e pretensamente neutra das comunidades científicas especializadas acaba por não se envolver com os conflitos, ou mesmo se opor às mobilizações por JA. E quando servem aos interesses dos grupos eco- nômicos mais poderosos, ocultam e manipulam incertezas relevantes, desenvolvem práticas não sistêmicas, não solidárias, e descartam ações precaucionárias de proteção da vida, sendo estratégico explicitá-las.

Há um permanente jogo de disputas entre argumentos que visam se livrar das possíveis responsabilidades frente às ameaças à vida das populações atingidas. Por exemplo: esta fábrica ou poluição é perigosa? Quem é responsável pela poluição do ar ou de um rio? Ou até que ponto está havendo um aumento real dos casos de câncer num dado território e grupo populacional? Ou como provar que eventuais aumentos estejam relacionados aos riscos produzidos por certo empreendimento? São questões chaves para os processos de regulação em saúde, licenciamento, fiscalização ou ainda os processos judiciais de reparação, mas a prática da ciência normal especializada raramente assume seu papel ético e político de defender a dignidade das populações atingidas. Não se trata de assumir uma defesa maniqueísta sem argumentos consistentes, mas de pôr em xeque a legitimidade de uma comunidade especializada ao definir isoladamente os parâmetros do problema e os critérios relevantes para a tomada de decisões.

Há uma forte conexão entre a produção compartilhada de conhecimentos e os direitos fundamentais, expressões tanto da soberania popular em sociedades democráticas quanto da noção de dignidade da pessoa humana. Isto inclui o direito ao meio ambiente ecologicamente equilibrado presente na Constituição brasileira, ou ainda o buen vivir da Constituição do Equador, ambos relacionados ao chamado princípio da precaução, cuja definição feita pela Unesco coloca em discussão riscos e situações perigosas moralmente inaceitáveis, por serem evitáveis e impostos a grupos socialmente discriminados, vulnerabilizando-os e violando sua dignidade. A produção acadêmica sobre JA vem sendo exemplar na inovação de estratégias engajadas e compartilhadas de produção de conhecimentos. Martinez-Alier et al..$^{32}$ mostram como movimentos por JA têm construído conceitos e agendas de pesquisa a partir de suas mobilizações e reflexões, tais como: epidemiologia popular, dívida ecológica, justiças climática e hídrica, defesa dos bens comuns e criminalização de ativistas. São inúmeras possibilidades para a produção de conhecimentos, incluindo a sistematização de fontes de informação e análises contextualizadas expressas, tanto por trabalhos acadêmicos e profissionais (livros, artigos e relatórios), como por outras linguagens: re- 
latos jornalísticos, livros não acadêmicos, filmes e fotos, produções literárias e artísticas diversas, depoimentos pessoais ou relatórios produzidos no âmbito de processos jurídicos. A participação direta de populações atingidas e organizações de JA produzem narrativas, inventários e mapeamentos dos conflitos ambientais, casos de poluição, acidentes, doenças e mortes relacionados com várias atividades econômicas e produtivas ${ }^{33}$. Os relatos significativos, por serem vivenciais e situados, não dissociam dimensões culturais e do cotidiano das dimensões técnicas, permitindo uma maior contextualização. Também difundem valores e alternativas sobre outros mundos possíveis, incluindo modos de vida, relações com a natureza e práticas solidárias de economia. Este é o caso de movimentos camponeses que lutam pela agroecologia, ou reivindicações das populações tradicionais para resguardarem suas tradições ${ }^{34}$.

Um aspecto central das iniciativas de produção de conhecimentos envolvendo populações atingidas e organizações de JA é a busca para se tornarem autônomos e sujeitos políticos capazes de conhecer e transformar a própria realidade ${ }^{35,36}$. Isto inclui a disputa pela validação de argumentos acerca dos problemas e controvérsias em questão, a partir de sua condição de sujeitos atingidos ou vulnerabilizados. Mas isso não impede o trabalho cooperativo com profissionais, cientistas e instituições, já que inúmeros problemas exigem o conhecimento especializado. Processos co-labor-ativos constroem laços de confiança em que cientistas e profissionais de diferentes áreas são solidários às denúncias, dispondo-se a trabalhar em contínuo diálogo com tais populações com base na pesquisa-ação.

Um caso exemplar é a proposta de epidemiologia popular ${ }^{36,37}$, originalmente criada para designar as atividades de detecção de perigos e busca de soluções empreendidas por grupos comunitários nos EUA, face a problemas de saúde decorrentes de algum tipo de contaminação ambiental. Sujeitos não especialistas coletam e organizam estatísticas e outras informações, ao mesmo tempo em que direcionam, contextualizam e refinam criticamente o conhecimento e os recursos de especialistas para entender a epidemiologia de uma doença. A epidemiologia popular assume o papel político de promover mobilizações sociais para o enfrentamento dos problemas investigados, sendo uma estratégia prática de se avançar na determinação social dos processos saúde-doença, já que as hipóteses causais levantadas não se limitam aos "fatores de risco" e sofisticadas correlações estatísticas. Questões sociais e éticas, como interesses industriais, decisões governamentais, normas de regulação, entre outras, são incorporadas na cadeia causal de doenças. De forma posterior e complementar, a pesquisa participativa de base comunitária (community -based participatory research - CBPR) configurase como uma ampla plataforma de pesquisa em saúde e ciências sociais, que busca compreender e abordar problemas de saúde e ambiente a partir de processos que conectam grupos ativistas e instituições de pesquisa.

Para finalizar comentaremos duas experiências recentes no Brasil, que apontam inovações importantes na articulação entre grupos de pesquisa, movimentos sociais e por JA. O primeiro diz respeito à incorporação dos mapas e informações territoriais acerca dos conflitos relacionados às injustiças ambientais e problemas de saúde ${ }^{38}$, construído em articulação com movimentos por JA e a Rede Brasileira de Justiça Ambiental. Posteriormente este trabalho se articulou a outros movimentos e Redes envolvendo distintos sujeitos políticos e agendas, como Agroecologia, Saúde Coletiva, Justiça Ambiental, Soberania Alimentar, Economia Solidária e Feminismo em torno da organização do Encontro Nacional de Diálogos e Convergências: agroecologia, saúde e justiça ambiental, soberania alimentar e economia solidária ${ }^{39}$. Tal articulação produziu o Intermapas, uma ferramenta dos movimentos sociais, redes e organizações para apoiar lutas nos territórios em torno desses movimentos e agendas, que integra quatro sistemas de informação georreferenciados, e conta com participação ativa de movimentos sociais, como: o Agroecologia em Rede, o Farejador da Economia Solidária, o Mapa de Conflitos Envolvendo Injustiça Ambiental e Saúde no Brasil, e, finalmente, o Mapa dos projetos financiados pelo BNDES. Desde então, o Intermapas tem sido utilizado nas chamadas Caravanas Territoriais como preparação para Encontros organizados pela Associação Nacional de Agroecologia, servindo como estratégia de animação, diálogo e formação dos debates políticos em diferentes territórios e regiões do país.

Outra experiência foi a construção do Dossiê da Abrasco sobre os impactos dos Agrotóxicos na Saúde ${ }^{40}$, em articulação com a Campanha Nacional Contra os Agrotóxicos e Pela Vida que envolve vários movimentos sociais e instituições. Em sua parte 3 foi desenvolvida uma metodologia denominada de Vozes do Território, uma proposta de "contraepistemologia" que pudesse acolher e valorizar a diversidade de conhecimentos das diferentes culturas e povos a partir do protago- 
nismo de diferentes sujeitos individuais e coletivos que viviam e trabalhavam nos territórios ${ }^{40}$. A incorporação do conceito de uma ecologia de saberes foi assumida para o diálogo com 19 relatos e depoimentos provenientes de diferentes regiões do país, inclusive comunidades indígenas. Neles os conflitos territoriais e as injustiças ambientais ganham vida pelas denúncias, mas também pela exposição e defesa dos valores, modos de vida e dimensões culturais que dão sentido às lutas desses sujeitos. Há, portanto, uma exposição sensível e contextualizadora dos problemas socioambientais e de saúde, vozes de camponeses e seus movimentos que compartilham suas experiências de transição agroecológica e resistências. Como apresenta o próprio Dossiê ${ }^{40}$, tratam-se de vozes que expressam não somente suas lutas contra as ameaças à vida, mas também a beleza e orgulho da alternativa agroecológica, "que entrelaça a alegria e reverência frente a uma natureza que entendem, respeitam e trabalham juntos", além dos laços de solidariedades e aprendizado coletivo que as experiências mais virtuosas de transição agroecológica e resistência ensinam.

\section{Considerações Finais}

Iniciamos este artigo apresentando os principais desafios do campo da saúde coletiva face à crise socioambiental contemporânea que intensifica os conflitos ambientais. Salientamos suas inter-relações como processos que desfiguram as sociedades e ecossistemas recém-incorporados à economia globalizada, reconfigurando as territorialidades de forma subalterna aos interesses dos grupos sociais hegemônicos de elites e países centrais. Tal visão rompe com a pretensa objetividade e neutralidade da prática científica para assumir posturas mais solidárias, co-labor-ativas e dialógicas de produção de conhecimentos.
O desafio epistêmico exige a crítica e superação dos aspectos descontextualizadores, reducionistas e despolitizantes do conhecimento construído a partir do paradigma hegemônico no campo da saúde. Para questionar esse paradigma nos aproximamos de abordagens emancipatórias, como os estudos pós-coloniais, que identificam a necessidade premente de questionarmos as fronteiras entre o conhecimento científico e o saber dos povos e comunidades vulnerabilizados. Esta aproximação nos impõe o desafio de superar hierarquias de saber consolidadas pelo avanço da tecnociência e relativizar seu poder, submetendo-a ao crivo de questionamentos éticos, políticos e epistêmicos. Ressaltamos tal possibilidade ao final do artigo através das experiências realizadas por produções de conhecimento com maior protagonismo dos movimentos por JA, que questionam as hierarquias, estruturas sociais e bases epistêmicas que legitimam as iniquidades socioambientais e em saúde.

A inter-relação entre os direitos humanos ou territoriais, as condições de vida e trabalho, o equilíbrio ambiental e a situação de saúde de comunidades tradicionais ou periferias urbanas, é um vasto campo a ser explorado e que merece maior atenção da saúde coletiva, pois muitos dos que hoje mais sofrem os impactos do modelo hegemônico de desenvolvimento e decorrente estrutura social são membros ou se originam de comunidades que conseguiram há muitos séculos atingir o objetivo de garantir a subsistência e a qualidade de vida humana com equilíbrio ambiental. Apesar disso, continuam sendo discriminados em sua condição de sujeitos e produtores de conhecimento. Reverter tal tendência é um belo desafio para a saúde coletiva e o conjunto da sociedade, para enfrentarmos a atual crise civilizatória que vivemos e caminharmos rumo à inevitável transição para um modelo de desenvolvimento mais justo e sustentável.

\section{Colaboradores}

MFS Porto, DF Rocha e R Finamore participaram igualmente de todas as etapas de elaboração do artigo. 


\section{Referências}

1. Rosen G. Uma história da Saúde Pública. São Paulo: UNESP, 1994

2. Czeresnia D. Do contágio à transmissão: uma mudança na estrutura perceptiva de apreensão da epidemia. História, Ciência e Saúde - Manguinhos 1997; 4(1):75-94.

3. Kuhn TS. A estrutura das revoluções científicas. São Paulo: Editora Perspectiva, 1987.

4. Barata RB. Epidemiologia social. Rev. Brasileira de Epidemiologia 2005; 8(1):7-17.

5. Iriart C, Waitzkin H, Breilh J, Estrada A, Merhy EE. Medicina social latinoamericana: aportes y desafíos. Rev. Panam Salud Publica 2002; 2(2):128-136.

6. Silva JB, Barros MBA. Epidemiologia e desigualdade: notas sobre a teoria e a história. Rev. Panam Salud Publica 2002; 12(6):375-383.

7. Gudynas E. Estado compensador y nuevos extractivismos. Nueva Sociedad 2012; 237:128-146.

8. Rodrigues VA. Observatório Internacional de Capacidades Humanas, Desenvolvimento e Políticas Públicas. Brasília: UnB, ObservaRH, Nesp; 2013.

9. Alvarez Castaño LS. Los determinantes sociales de la salud: más allá de los factores de riesgo. Rev. Gerenc Polit Salud 2009; 8(17).

10. Castellanos PL. Sobre el concepto de Salud-enfermedad. Un punto de vista epidemiológico. Rev. Facultad Nacional de Salud Publica 1988; 11:40-55.

11. Sabroza P. Estudos epidemiológicos na perspectiva do aumento da vulnerabilidade dos sistemas sócio-ambientais brasileiros. Epidemiol Serv Saúde 2007; 16(4): 229-233.

12. Levins R, Lopez C. Toward an ecosocial view of health. Int J Health Serv 1999; 29(2):261-294

13. Krieger N. Theories for social epidemiology in the $21 \mathrm{st}$ century: an ecosocial perspective. Int J Epidemiol 2001; 30(4):668-677.

14. Buzzelli M. Bourdieu does environmental justice? Probing the linkages between population health and air pollution epidemiology. Health \& Place 2007; 13:3-13

15. Bourdieu P. O poder simbólico. $12^{\text {a }}$ ed. Rio de Janeiro: Bertrand Brasil; 2009.

16. Williams GH. The determinants of health: structure, context and agency. Sociology of Health \& Illness 2003; 25(3):131-154.

17. Rattner H. Meio ambiente, saúde e desenvolvimento sustentável. Cien Saude Colet 2009; 14(6):1965-1971.

18. Haesbaert R, Ramos T. O mito da desterritorialização económica. GEOgraphia 2004; 6(12):25-48.

19. Porto MFS, Pacheco T. Conflitos e injustiça ambiental em saúde no Brasil. Tempus - Actas em Saúde Coletiva 2009; 3(4):26-37.

20. M'Gonigle M. Ecological economics and political ecology: towards a necessary synthesis. Ecological Economics 1999; 28:11-26.

21. Porto MFS, Martínez-Alier J. Ecologia política, economia ecológica e saúde coletiva: interfaces para a sustentabilidade do desenvolvimento e para a promoção da saúde. Cad Saude Publica 2007; 23(Supl. 4):S503-S512.

22. Acselrad H. Vulnerabilidade ambiental, processos e relações. In: Anais do Encontro Nacional de Produtores e Usuários de Informações sociais, Econômicas e Territoriais; Rio de Janeiro. p. 21-26.
23. Porto MFS. Complexidade, processos de vulnerabilização e justiça ambiental: Um ensaio de epistemologia política. Rev. Crítica de Ciências Sociais 2011; 93:31-58.

24. Nunes JA. Saúde, direito à saúde e justiça sanitária. Rev Crítica de Ciências Sociais 2009; 87:143-169.

25. Monken M, Peiter P, Barcellos C, Rojas LI, Navarro MA, Gondim GMM, Gracie R. O território em saúde: construindo referências para análises em saúde e ambiente. In: Miranda AC, Barcellos C, Moreira JC, Monken M, organizadores. Território, Ambiente e Saúde. Rio de Janeiro: Fiocruz; 2008. p. 23-41.

26. Lander E, organizador. A colonialidade do saber: eurocentrismo e ciências sociais - Perspectivas latino-americanas. Buenos Aires: CLACSO; 2005.

27. Borde E. Notas para uma reinterpretação dos processos de determinação social das iniquidades étnico-raciais em saúde [dissertação]. Rio de Janeiro: Escola Nacional de Saúde Pública Sergio Arouca; 2014.

28. Ballestrin L. América latina e o giro decolonial. Rev. Brasileira de Ciência Política 2013; 11:89-117.

29. Santos BS, Meneses MP. Epistemologias do Sul. São Paulo: Cortez; 2010

30. Mignolo W. Desobediencia epistémica: retórica de la modernidad, lógica de la colonialidad y gramática de la descolonialidad. Buenos Aires: Ediciones del Signo; 2010.

31. Santos BS. A gramática do tempo: para uma nova cultura política. 3a ed. São Paulo: Cortez; 2010.

32. Martinez-Alier J, Anguelovski I, Bond P, Del Bene D, Demaria F, Gerber JF, Greyl L, Haas W, Healy H, Burgos VM, Ojo G, Porto M, Rijnhout L, Rodríguez-Labajos B, Spangenberg J, Temper L, Warlenius R, Yánez I. Between activism and science: grassroots concepts for sustainability coined by Environmental Justice Organizations. Journal of Political Ecology 2014; 21:19-60.

33. Porto MFS, Finamore R, Rocha DF. Health as Dignity: Risks, Health and Environmental Justice Mobilizations. EJOLT Report. No prelo 2014.

34. Rigotto RM, Carneiro FF, Marinho AMCP, Rocha MM, Ferreira MJM, Pessoa VM, Teixeira ACA, Silva ALV, Braga LQV, Teixeira MM. O verde da economia no campo: desafios à pesquisa e às políticas públicas para a promoção da saúde no avanço da modernização agrícola. Cien Saude Colet 2012; 17(6):1533-1542.

35. Corburn J. Street Science: Community Knowledge and Environmental Health Justice. Cambridge: MIT Press; 2005.

36. Brown P. Popular Epidemiology: Community Response to Toxic Waste-Induced Disease in Woburn, Massachusetts. Sci Technol Human Values 1987; 12(3/4):7885

37. Porto MFS, Finamore R. Riscos, saúde e justiça ambiental: o protagonismo das populações atingidas na produção de conhecimento. Cien Saude Colet 2012; 17(6): 1493-1501.

38. Porto MF, Pacheco T, Leroy JP, organizadores. Injustiça Ambiental e Saúde no Brasil: O Mapa de Conflitos. Rio de Janeiro: Fiocruz; 2013. 
39. Carta Política do Encontro Nacional de Diálogos e Convergências. Salvador; 2011 [acessado 2012 mar 20]. [documento da internet]. Disponível em: http://goo. $\mathrm{gl} / \mathrm{dXNSB}$

40. Abrasco. Dossiê Abrasco. Agrotóxicos, conhecimento científico e popular: construindo a ecologia de saberes. Porto Alegre: Abrasco; 2012. (Parte 3)

Artigo apresentado em 02/07/2014

Aprovado em 11/07/2014

Versão final apresentada em 12/07/2014 